\title{
Vitamin D status and cardiometabolic risk factors in Greek adolescents with obesity - the effect of vitamin D supplementation: a pilot study
}

Stefania E. Makariou ${ }^{1}$, Anna Challa ${ }^{1}$, Ekaterini Siomou ${ }^{1}$, Constantinos Tellis², Alexandros Tselepis², Moses Elisaf ${ }^{3}$, Evangelos Liberopoulos ${ }^{3}$

\author{
${ }^{1}$ Department of Child Health, Medical School, University of Ioannina, Ioannina, Greece \\ ${ }^{2}$ Laboratory of Biochemistry, Department of Chemistry, University of Ioannina, \\ loannina, Greece \\ ${ }^{3}$ Department of Internal Medicine, Medical School, University of Ioannina, Ioannina, \\ Greece
}

Submitted: 11 March 2020

Accepted: 21 April 2020

Arch Med Sci Atheroscler Dis 2020; 5: e64-e71

DOI: https://doi.org/10.5114/amsad.2020.95569

Copyright (c) 2020 Termedia \& Banach

\begin{abstract}
Introduction: Obesity is associated with cardiovascular disease (CVD) risk factors as well as decreased $25(\mathrm{OH})$ vitamin $\mathrm{D}$ serum levels. We aimed to study $25(\mathrm{OH})$ vitamin D levels in adolescents with obesity compared with normal weight controls in association with CVD risk factors, and the possible effect of vitamin D supplementation.

Material and methods: In a cross-sectional study, 69 obese and 34 normal-weight adolescents were included. In an interventional study 15 adolescents with obesity and vitamin D insufficiency were given 2000 IU vitamin D per os daily for 3 months.

Results: Adolescents with obesity had significantly lower $25(\mathrm{OH})$ vitamin $D$ levels compared with normal-weight controls (12.0 (3.0-36.0) vs. 34.0 (10.069.0) $\mathrm{ng} / \mathrm{ml}$, respectively, $p<0.001)$. In adolescents with obesity, $25(\mathrm{OH}) \mathrm{vi}$ tamin $\mathrm{D}$ was inversely associated with leptin even after adjustment for body mass index (BMI) $(r=-0.340, p=0.009)$. Conversely, 25(OH) vitamin D was not related with other parameters, such as BMI, blood pressure, lipids, glucose, insulin, homeostasis model assessment (HOMA) index, adiponectin, leptin/adiponectin ratio, and visfatin levels. Following supplementation in 15 vitamin $D$ insufficient adolescents with obesity, $25(\mathrm{OH})$ vitamin $D$ significantly increased (from $17.3(12.5-27.8)$ to $32.6(14.3-68.0) \mathrm{ng} / \mathrm{ml}, p=$ 0.005 ) and so did low-density lipoprotein cholesterol (LDL-C) (from $85.4 \pm 9.5$ to $92.1 \pm 15.8 \mathrm{mg} / \mathrm{dl}, p=0.022$ ), while there were reductions in glycated haemoglobin $\left(\mathrm{HbA}_{1 \mathrm{C}}\right.$ ) (from $5.8 \pm 0.2$ to $5.5 \pm 0.1 \%, p=0.03$ ) and leptin (from 19.7 $(7.8-45.5)$ to $15.1(4.3-37.3) \mathrm{ng} / \mathrm{ml}, p=0.03)$. Oxidised LDL, paraoxonase, arylesterase, and urine isoprostanes remained unchanged.

Conclusions: Adolescents with obesity had lower $25(\mathrm{OH})$ vitamin D, which may be associated with higher leptin levels. Vitamin D supplementation may lead to $\mathrm{HbA}_{1 \mathrm{c}}$ and leptin reductions, but also to an increase in LDL-C.
\end{abstract}

Key words: obesity, cardiovascular risk factors, adolescents, $25(\mathrm{OH})$ vitamin D.

\section{Introduction}

During the last decade great attention has been given to the multi-modal actions of vitamin D (VitD) in humans as well as to the pos-

\author{
Corresponding author: \\ Assoc. Prof. Evangelos \\ Liberopoulos MD \\ Department of \\ Internal Medicine \\ School of Medicine \\ University of loannina \\ loannina 45 110, Greece \\ Phone: +30 2651007509 \\ E-mail: elibero@uoi.gr, \\ makarioustefania@yahoo. \\ com
}


sible adverse effects of its deficiency in all age groups. To define VitD deficiency/insufficiency, serum 25-hydroxy-VitD [25(OH)VitD] levels < 20/ $<30 \mathrm{ng} / \mathrm{ml}$, respectively, are commonly used according to the Institute of Medicine guidelines [1]. Of note, a recent consensus indicates that $25(\mathrm{OH})$ VitD > $20 \mathrm{ng} / \mathrm{ml}$ appears to be safe and sufficient in the general population regarding skeletal health [2]. Hypovitaminosis D in children and adolescents seems to be a re-emerging public health problem in developed countries. The prevalence of VitD deficiency/insufficiency is estimated to be $9 / 60 \%$, respectively, in the US [3], 25.7-62.9\% VitD insufficiency in Europe [4], and 5.2/52.5\% of VitD deficiency/insufficiency, respectively, in Greece [5]. Among other risk factors for hypovitaminosis $D$ in childhood and adolescence, obesity plays a prominent role, since $23.2 \%$ of the population aged between 2 and 19 years in developed countries are overweight or obese (2013 data) [6]. Studies in children and adolescents have shown possible associations of low 25(OH)VitD levels with cardiovascular disease (CVD) risk factors, albeit not consistently and to a lesser extent compared with adults $[3,7]$. Although the association between hypovitaminosis D and obesity is well established, there is still controversy over its cause and effect mode and its actual impact on health.

The present study sought to examine the prevalence of VitD deficiency/insufficiency among Greek adolescents with obesity and the possible association of 25(OH)VitD serum levels with classic and emerging CVD risk factors, including oxidative stress markers and adipokines. We also investigated the effect of VitD supplementation on these risk factors in a group of participants with deficiency/insufficiency.

\section{Material and methods}

\section{Study population}

Adolescents attending the Outpatient Paediatric and the Metabolic and Obesity Clinics of the University Hospital of Ioannina, Ioannina, Greece, were included in this study. In a cross-sectional study, 69 obese and 34 age- and sex-matched, normal-weight adolescents were tested for 25(OH)VitD levels and several CVD risk factors. Thereafter, in a prospective/interventional study, 15 adolescents with obesity and VitD insufficiency/deficiency were given 2000 IU VitD per os daily plus dietary instructions and were re-evaluated after 3 months.

All adolescents were weighed on a digital scale, and height measurement was performed with a stable stadiometer, barefoot, and wearing light clothing. Body mass index (BMI) is defined as weight (kilograms) divided by height squared $\left(m^{2}\right)$. According to Centre for Disease Control and Prevention guidelines, BMI between the $5^{\text {th }}$ and $84^{\text {th }}$ percentile for age and sex is considered as healthy weight, $85^{\text {th }}-94^{\text {th }}$ percentile as overweight, and $\geq 95^{\text {th }}$ percentile as obese [8]. Severe obesity was defined as $\mathrm{BMI} \geq 120 \%$ of the $95^{\text {th }}$ percentile for age and sex or BMI $>35 \mathrm{~kg} / \mathrm{m}^{2}$, whichever was lower [9]. Blood pressure was measured in a sitting position after a 5-minute rest, using a digital sphygmomanometer (Omron M3 HEM-7131), and the mean of two measurements was recorded. Hypertension was defined as systolic or diastolic blood pressure $>95^{\text {th }}$ percentile according to age, sex, and percentile of height [10]. All blood samples were taken after an overnight fast. For the analysis, all CVD risk factors considered as abnormal were based on the definitions by the National Cholesterol Education Program Adult Treatment Panel III (NCEP ATP-III) modified for age [11]. These were: waist circumference $\geq 90^{\text {th }}$ percentile for age and sex, high-density lipoprotein (HDL) cholesterol $\leq 40 \mathrm{mg} / \mathrm{dl}$, triglycerides $\geq 110 \mathrm{mg} / \mathrm{dl}$, and fasting glucose $\geq 100 \mathrm{mg} / \mathrm{dl}$. Patients with diabetes, chronic kidney or liver diseases, triglycerides $>500 \mathrm{mg} / \mathrm{dl}$, and on calcium and/or VitD supplements as well as on lipid-lowering medications or anti-hypertensive drugs were excluded. The pubertal stage was estimated with the Tanner scale.

In the second part of the study we administered $2000 \mathrm{IU} \mathrm{VitD}_{3}$ /day per os (caps Vitamin $\mathrm{D}_{3}$ Lamberts $^{\circledR}$ ) for 3 months to adolescents with obesity to correct their VitD insufficiency/deficiency taking into consideration current recommendations $[12,13]$. Participants also followed a 12-week dietary intervention program. That included a moderate carbohydrate and increased protein diet, which provided $40-45 \%$ of total energy as carbohydrate (moderate glycaemic load), 30\% fat ( $\leq$ $10 \%$ saturated fat), and $25-30 \%$ protein. Two different energy levels were assigned, depending upon age: 6000-7000 kJ (10-14 years old) or 7000-8000 kJ (15-17 years old). The dietary intervention conferred $2000 \mathrm{~kJ}$ less than the recommended intake for age and promoted an increase in incidental activity and a decrease in sedentary behaviour [14]. The compliance to dietary instructions was assessed by completing food diaries and through discussion during follow-up visit, while compliance with study medication was checked by tablet count at week 12; patients were considered compliant if they received $80-100 \%$ of the prescribed tablets.

To minimise the effect of sunlight on $25(\mathrm{OH})$ VitD levels, all blood specimens were collected during March to September, a season during which the duration of sunlight is approximatively similar in Greece.

The study was carried out in accordance with the Code of Ethics of the World Medical Asso- 
ciation (Declaration of Helsinki), and written, informed consent was obtained from all participants and their parents/guardians.

\section{Laboratory measurements}

All laboratory tests were carried out after an overnight fast at baseline and 12 weeks after the intervention.

Serum 25(OH)VitD levels were measured quantitatively by an enzyme-linked immunosorbent assay (ELISA) method using the kit by DRG Instruments GmbH (DRG, Marburg, Germany). The method's analytical sensitivity was $1.28 \mathrm{ng} / \mathrm{ml}$, and the intra- and inter-assay coefficients of variation (CVs) were $7 \%$ at the level of $30 \mathrm{ng} / \mathrm{ml}$.

Total cholesterol (TCHOL), triglycerides (TGs), and high-density lipoprotein cholesterol (HDL-C) were measured enzymatically on an Olympus AU600 Clinical Chemistry analyser (Olympus Diagnostica, Hamburg, Germany). The Friedewald formula was used to calculate serum low-density lipoprotein cholesterol (LDL-C) (when triglycerides were < $350 \mathrm{mg} / \mathrm{dl}$ ). Serum insulin was determined on an AXSYM analyser by a microparticle enzyme immunoassay (Abbott Diagnostika, Wiesbaden-Delkenheim, Germany) with a coefficient of variation of $4.2-9.0 \%$. The homeostasis model assessment (HOMA) index was calculated using the formula: fasting insulin $(\mathrm{mlU} / \mathrm{l}) \times$ fasting glucose $(\mathrm{mg} / \mathrm{dl}) / 405$. The determination of glycated haemoglobin $\left(\mathrm{HbA}_{1 \mathrm{c}}\right)$ was based on a latex agglutination inhibition assay (Randox Laboratories Ltd., Antrim, UK). $\mathrm{HbA}_{1 \mathrm{c}}$ values are expressed as percentage of the total haemoglobin concentration. The sensitivity of the method is $0.25 \mathrm{~g} / \mathrm{dl}$ of $\mathrm{HbA} 1 \mathrm{c}$ and the within-run and between-run precision are $<6.67 \%$ and $<4.82 \%$, respectively. Serum intact parathyroid hormone (iPTH) was measured by IMMULITE 2500 Intact PTH, a solid-phase, twosite, chemiluminescent, enzyme labelled immunometric assay (Siemens Medical Solutions Diagnostics, Los Angeles, CA 90045-6900, USA).

Leptin was determined using a human leptin ELISA kit purchased from BioVendor (Czech Republic) following the manufacturer's instructions. The coefficient of variation was $<7 \%$. Each concentration obtained was determined from the standard curve. Plasma levels of total adiponectin were determined using the adiponectin multimeric enzyme immunoassay (ALPCO DIAGNOSTICS, Salem, NH, USA) according to the manufacturer's protocol. The intra-assay coefficient of variation (CV) was $5.4 \%$. Visfatin was determined by a competitive enzyme immunoassay method using the kit by Phoenix Pharmaceuticals, Inc. (USA). The intra-assay CV was $<10 \%$.

Plasma levels of oxidised low-density lipoprotein (ox-LDL) were measured by a competitive enzyme-linked immunosorbent assay using a specific murine monoclonal antibody (4E6) according to the instructions provided by the manufacturer (Mercodia, Uppsala, Sweden) as previously described. Intra- and inter-assay coefficients of variation were $6.0 \%$ and $7.0 \%$, respectively. The paraoxonase-1 (PON-1) activities in serum were measured using paraoxon (paraoxonase activity) or phenylacetate (arylesterase activity), as a substrate. Both PON-1 activities were determined in the presence of $2 \mathrm{mM} \mathrm{Ca}^{2+}$ in $100 \mathrm{mM}$ Tris- $\mathrm{HCl}$ buffer $(\mathrm{pH}$ 8.0) for paraoxon and in $20 \mathrm{mM}$ Tris- $\mathrm{HCl}$ buffer ( $\mathrm{pH}$ 8.0) for phenyl acetate. Urine levels of 8-isoprostane (8-epiPGF2a) were determined by a competitive enzyme immunoassay (commercial 8-isoprostane EIA kit, Cayman Chemicals, Ann Arbor, $\mathrm{MI}$ ), following the manufacturer's instructions. The 8-epiPGF2a levels in urine were expressed as $\mathrm{ng} / \mathrm{mmol}$ creatinine.

\section{Statistical analysis}

This was a pilot study, and therefore formal power calculations were not performed. Data are presented as mean and standard deviation except for non-Gaussian distributed variables, which are presented as median (range). Preliminary analyses were performed to ensure no violation of the assumptions of normality and linearity. The Kolmogorov-Smirnov test was used to evaluate whether each variable followed a Gaussian distribution. The independent samples $t$-test (or Mann-Whitney $U$-test when required) was used to assess differences between groups (obese, normal weight). The relationships among study variables were investigated by use of the Pearson product moment correlation coefficient, whereas correlations including at least one non-Gaussian distributed variable were performed with the Spearman correlation coefficient. The paired samples $t$-test or the Wilcoxon signed-rank test was used to assess the effect of treatment in the intervention group. A $p$-value $\leq 0.03$ was considered to be significant due to multiple comparisons (Bonferroni correction). All analyses were carried out with the SPSS 18 software package (SPSS Inc., 1989-2004, Chicago, IL).

\section{Results}

\section{Cross-sectional study}

Baseline clinical characteristics and laboratory findings of the study participants $(n=103,69$ obese and 34 normal weight) are shown in Table I. The two groups had significant differences in weight, BMI, waist circumference (WC), systolic blood pressure (SBP), diastolic blood pressure (DBP), insulin, HOMA index, TGs, HDL-C, leptin levels, and leptin/adiponectin ratio. Adolescents 
Table I. Baseline characteristics of the study participants

\begin{tabular}{|c|c|c|c|}
\hline Parameter & Adolescents with obesity $(n=69)$ & Normal weight $(n=34)$ & $P$-value \\
\hline Sex (boys/girls) & $31 / 38$ & $15 / 19$ & 0.542 \\
\hline Age [years] & $12.0 \pm 2.0$ & $12.6 \pm 2.0$ & 0.538 \\
\hline Weight [kg] & $74 \pm 21$ & $47 \pm 12$ & $<0.001$ \\
\hline $\mathrm{BMI}\left[\mathrm{kg} / \mathrm{m}^{2}\right]$ & $29.7 \pm 5.5$ & $19.6 \pm 2.3$ & $<0.001$ \\
\hline$W C[\mathrm{~cm}]$ & $92 \pm 13$ & $69 \pm 7$ & $<0.001$ \\
\hline $\mathrm{SBP}[\mathrm{mm} \mathrm{Hg}]$ & $123 \pm 9$ & $108 \pm 9$ & $<0.001$ \\
\hline $\mathrm{DBP}[\mathrm{mm} \mathrm{Hg}]$ & $71 \pm 10$ & $68 \pm 7$ & 0.04 \\
\hline Glucose $[\mathrm{mg} / \mathrm{dl}]$ & $87 \pm 8.0$ & $86 \pm 8.0$ & 0.284 \\
\hline Insulin $[\mu \mathrm{U} / \mathrm{ml}]$ & $13(6-43)$ & $8(2-16)$ & $<0.001$ \\
\hline HOMA index & $2.8(1.2-9.6)$ & $1.7(0.4-3.6)$ & $<0.001$ \\
\hline TCHOL $[\mathrm{mg} / \mathrm{dl}]$ & $168 \pm 30$ & $169 \pm 16$ & 0.555 \\
\hline TGs $[\mathrm{mg} / \mathrm{dl}]$ & $103(50-222)$ & $79(28-123)$ & 0.005 \\
\hline $\mathrm{HDL}-\mathrm{C}[\mathrm{mg} / \mathrm{dl}]$ & $42 \pm 9$ & $50 \pm 8$ & $<0.001$ \\
\hline LDL-C [mg/dl] & $104 \pm 25$ & $102 \pm 16$ & 0.968 \\
\hline Leptin [ng/ml] & $36(7-105)$ & $8(1-27)$ & $<0.001$ \\
\hline Adiponectin $[\mu \mathrm{g} / \mathrm{ml}]$ & $8 \pm 5$ & $8 \pm 4$ & 0.987 \\
\hline Leptin/adiponectin ratio & $7.4 \pm 5.7$ & $1.5 \pm 1.1$ & $<0.001$ \\
\hline Visfatin [ng/ml] & $15 \pm 8$ & $16 \pm 7$ & 0.621 \\
\hline $25(\mathrm{OH}) \mathrm{VitD}[\mathrm{ng} / \mathrm{ml}]$ & $12(3-36)$ & $34(10-69)$ & $<0.001$ \\
\hline
\end{tabular}

$B M I$ - body mass index, WC - waist circumference, SBP - systolic blood pressure, DBP - diastolic blood pressure, HOMA - homeostasis model assessment, TCHOL - total cholesterol, HDL-C - high-density lipoprotein cholesterol, LDL-C - low-density lipoprotein cholesterol, $T G s$ - triglycerides, 25(OH)Vit D - 25-hydroxy vitamin D. To convert values to mmol/L for triglycerides multiply by 0.01129 , for cholesterol by 0.02586 , for glucose by 0.05551 , and for $25(\mathrm{OH})$ Vit $D$ by 2.5 .

with obesity had lower 25(OH)VitD compared with normal-weight controls $(12.0(3.0-36.0)$ vs. $34.0(10.0-69.0) \mathrm{ng} / \mathrm{ml}$ respectively, $p<0.001)$. Overall, $74.7 \%$ of the study participants had VitD insufficiency $(25[\mathrm{OH}] \mathrm{VitD}<30 \mathrm{ng} / \mathrm{ml})$ and $52.4 \%$ VitD deficiency $(25[\mathrm{OH}] \mathrm{VitD}<20 \mathrm{ng} / \mathrm{ml})$. Furthermore, the prevalence of deficiency was higher among obese (73.9\%) compared with normal-weight adolescents (17.6\%).

In the subjects with obesity, 25(OH)VitD was inversely related to leptin in univariate analysis $(r=-0.280, p=0.037)$ (Table II), which persisted after adjustment for BMI ( $r=-0.340, p=0.009)$. In contrast, 25(OH)VitD was not associated with weight, BMI, WC, SBP, DBP, TCHOL, HDL-C, LDL-C, TGS, glucose, insulin, HOMA index, leptin/adiponectin ratio, adiponectin, or visfatin (Table II).

\section{Prospective study}

Table III shows the clinical characteristics and laboratory findings at baseline and after intervention of adolescents with obesity and VitD insufficiency/deficiency $(n=15)$ who were given VitD supplementation along with dietary instructions. Over half of them (9 out of $15,60 \%$ ) were VitD deficient $(25[\mathrm{OH}]$ VitD $<20 \mathrm{ng} / \mathrm{ml})$. Three months later, $25(\mathrm{OH})$ VitD increased significantly by $88.4 \%$ (from 17.3 (12.5-27.8) to $32.6(14.3-68.0) \mathrm{ng} / \mathrm{ml}$, $p=0.005)$ (Table III). Interestingly, at the same time, marginally significant reductions were seen in $\mathrm{HbA}_{1 \mathrm{c}}(p=0.03)$ and leptin levels $(p=0.03)$. Conversely, LDL-C levels significantly increased $(p=0.022)$. Other clinical and laboratory metabolic parameters (BMI, WC, DBP, TCHOL, HDL-C, TGs, glucose, insulin, HOMA index, $\mathrm{PTH}$ ) along with oxidative stress markers (oxidised-LDL, paraoxonase, arylesterase, and urine isoprostanes) remained unchanged (Table III). No significant correlation between relative changes of clinical and laboratory variables following VitD supplementation was found (data not shown).

\section{Discussion}

In this study, we observed that VitD deficiency was more prevalent among Greek adolescents with obesity $(73.9 \%$ vs. $17.6 \%$ in normal-weight 
Table II. Univariate correlations of log 25(OH)VitD with metabolic parameters in adolescents with obesity

\begin{tabular}{|lcc|}
\hline Parameter & $r$ & $P$-value \\
\hline Weight & 0.149 & 0.221 \\
\hline BMI & 0.196 & 0.107 \\
\hline WC & 0.151 & 0.259 \\
\hline SBP & 0.313 & 0.089 \\
\hline DBP & 0.206 & 0.092 \\
\hline Glucose & -0.139 & 0.260 \\
\hline Log (Insulin) & -0.073 & 0.558 \\
\hline Log (HOMA index) & -0.085 & 0.493 \\
\hline TCHOL & -0.178 & 0.147 \\
\hline Log (TGs) & -0.010 & 0.932 \\
\hline HDL-C & -0.120 & 0.329 \\
\hline LDL-C & -0.205 & 0.096 \\
\hline Log (Leptin) & -0.280 & $0.037^{\star}$ \\
\hline Adiponectin & -0.281 & 0.058 \\
\hline Leptin/adiponectin & 0.029 & 0.839 \\
ratio & -0.175 & 0.223 \\
\hline Visfatin & $-60 d y$ ass & $W C-w a i s t$
\end{tabular}

Log - decimal logarithm, BMI - body mass index, WC - waist circumference, $S B P$ - systolic blood pressure, $D B P$ - diastolic blood pressure, HOMA - homeostasis model assessment, TCHOL - total cholesterol, HDL-C - high-density lipoprotein cholesterol, LDL-C - low-density lipoprotein cholesterol, TGs - triglycerides, 25(OH) Vit $D-25$-hydroxy vitamin $D$.

controls). VitD supplementation (2000 IU/day per os for 3 months) in those with insufficiency/deficiency effectively increased 25(OH)VitD levels and was associated with marginal decreases in $\mathrm{HbA}_{10}$ and leptin as well as an increase in LDL-C levels.

Recent studies worldwide report high incidences of suboptimal VitD status in obese youths (70\%) [15], in agreement with our results, which have been attributed to several reasons. Individuals with obesity have inadequate sun exposure mainly due to lack of outdoor activities, resulting in reduced VitD skin synthesis. These individuals also usually consume junk food that contains minimum quantities of VitD. Moreover, fat-soluble VitD is sequestrated in adipocytes, which decreases its bioavailability [16].

In this regard, much attention has been paid to the possible effect of VitD deficiency on several CVD risk factors. However relative data in childhood and adolescence are sparse and results from observational and interventional studies are controversial. Accumulating evidence has indicated that serum $25(\mathrm{OH})$ VitD levels may be negatively associated with blood pressure in most $[3,17$,
18], but not all [19], studies. Interestingly, a recent analysis from NHANES 2007-2010 $(n=2908$ aged 8-18 years) showed that 25(OH)VitD was not associated with SBP when adjusting for BMI [20]. In our study also no correlation was detected between 25(OH)VitD levels and SBP or DBP in adolescents with obesity. The recently published ODIN Project assigned adolescents ( $n=110$ white, healthy, $81 \%$ normal weight, $14-18$ years) to receive either placebo or VitD (400 or 800 IU/day) for 20 weeks and found no effect on SBP or DBP [21]. In our study, after VitD supplementation we found a small but not significant reduction in SBP by $3.9 \%$ (from $134 \pm 11$ to $129 \pm 17 \mathrm{~mm} \mathrm{Hg}, p=$ $0.043)$, while DBP did not change significantly. Studies regarding the relationship between VitD status and lipid profile in children/adolescents with obesity have also reported inconsistent results, with some being positive [22] and others not $[19,23]$. 25(OH)VitD has been reported to be inversely related to TCHOL [24] and TGs [25], negatively [24] or positively to LDL-C [26], and positively to $\mathrm{HDL}-\mathrm{C}$ levels $[3,15,27]$. In the present study we found no relationship between 25(OH)VitD levels and lipids. Also, two interventional studies found no change in lipid profile after VitD supplementation [21,28]. In our study we found an increase of $7.8 \%$ in LDL-C levels after VitD supplementation, while other lipids remained unchanged. To our knowledge, this finding has not been previously reported in adolescents. However, a meta-analysis of randomised controlled trials (RCTs) in adults also led to the conclusion that VitD supplementation significantly increased LDL-C levels [29]. Moreover, many cross-sectional studies in young ages showed that 25(OH)VitD levels correlated with fasting glucose [30, 31], fasting insulin [32, 33], and/or HOMA-IR [19, 32, 34] while some did not $[35,36]$. Similarly, in the present study $25(\mathrm{OH})$ VitD was not found to be associated with any carbohydrate metabolism marker. Whether VitD supplementation would improve insulin sensitivity and glucose metabolism in childhood and adolescence is controversial. Some RCTs showed beneficial effects on insulin sensitivity $[13,28]$ while others Did not [33, 35, 37]. In this study, adolescents with obesity, VitD insufficiency/deficiency, and insulin resistance (median HOMA-IR 3.7), who received VitD supplementation, had a $5.2 \%$ reduction in $\mathrm{HbA}_{1 c}$ levels but no changes in fasting glucose, fasting insulin, and HOMA-IR for the time studied. Conversely, $\mathrm{HbA}_{1 \mathrm{c}}$ levels were not affected by $V i t D$ supplementation in adolescents with obesity in another study [13].

With regard to oxidative stress, previous studies have shown that VitD deficiency may be implicated even in youth. Also, VitD supplementation is reported to have a favourable effect on the antioxidant system [38]. In our study, however, treatment 
Table III. Metabolic parameters of adolescents with obesity and VitD insufficiency/deficiency $(n=15)$ at baseline and 3 months after VitD supplementation (2000 IU/day) and dietary intervention

\begin{tabular}{|c|c|c|c|c|}
\hline Variable & Baseline & 3 Months & $\begin{array}{l}P \text {-value vs. } \\
\text { baseline }\end{array}$ & Change, \% \\
\hline$N$ (males/females) & $15(10 / 5)$ & & & \\
\hline Age [years] & $15.4 \pm 1.8$ & & & \\
\hline Smoking (yes/no) & $5 / 10$ & $5 / 10$ & & \\
\hline Weight $[\mathrm{kg}]$ & $97.6 \pm 16.9$ & $96.4 \pm 19.5$ & 0.140 & -1.3 \\
\hline $\mathrm{BMI}\left[\mathrm{kg} / \mathrm{m}^{2}\right]$ & $35.0 \pm 7.9$ & $34.1 \pm 8.4$ & 0.130 & -2.6 \\
\hline$W C[\mathrm{~cm}]$ & $115.6 \pm 1.2$ & $114.6 \pm 1.5$ & 0.123 & -0.8 \\
\hline $\mathrm{SBP}[\mathrm{mm} \mathrm{Hg}]$ & $134 \pm 11$ & $129 \pm 17$ & 0.043 & -3.9 \\
\hline $\mathrm{DBP}[\mathrm{mm} \mathrm{Hg}]$ & $75 \pm 8$ & $73 \pm 10$ & 0.158 & -3.0 \\
\hline TCHOL $[\mathrm{mg} / \mathrm{dl}]$ & $154.8 \pm 10.9$ & $163.4 \pm 15.5$ & 0.190 & +5.5 \\
\hline $\mathrm{HDL}-\mathrm{C}[\mathrm{mg} / \mathrm{dl}]$ & $40.0 \pm 4.7$ & $40.8 \pm 5.0$ & 0.874 & +2.0 \\
\hline LDL-C [mg/dl] & $85.4 \pm 9.5$ & $92.1 \pm 15.8$ & $0.022^{*}$ & +7.8 \\
\hline TGs [mg/dl] & $83.0(65.0-208.0)$ & $76.0(56.0-188.0)$ & 0.570 & -8.4 \\
\hline Fasting glucose $[\mathrm{mg} / \mathrm{dl}]$ & $88.6 \pm 8.9$ & $89.6 \pm 7.7$ & 0.475 & +1.1 \\
\hline Fasting insulin $[\mu \mathrm{U} / \mathrm{ml}]$ & $15.4(7.1-18.7)$ & $13.9(7.9-20.0)$ & 0.979 & -9.7 \\
\hline HOMA index & $3.7(1.3-4.4)$ & $2.9(1.8-4.9)$ & 0.745 & -21.6 \\
\hline $\mathrm{HbA}_{1 c}(\%)$ & $5.8 \pm 0.2$ & $5.5 \pm 0.1$ & $0.03^{\star}$ & -5.2 \\
\hline Leptin $[\mathrm{ng} / \mathrm{ml}]$ & $19.7(7.8-45.5)$ & $15.1(4.3-37.3)$ & $0.03^{*}$ & -23.3 \\
\hline $25(\mathrm{OH}) \mathrm{VitD}[\mathrm{ng} / \mathrm{ml}]$ & $17.3(12.5-27.8)$ & $32.6(14.3-68.0)$ & $0.005^{*}$ & +88.4 \\
\hline iPTH [pg/ml] & $32.0 \pm 16.6$ & $37.5 \pm 13.3$ & 0.732 & +17.2 \\
\hline Ox-LDL [U/I] & $56.5 \pm 12.4$ & $57.3 \pm 14.6$ & 0.215 & +1.4 \\
\hline Paraoxonase [U/I] & $59.8(47.6-151.4)$ & $61.5(51.5-161.3)$ & 0.670 & +2.8 \\
\hline Arylesterase [U/ml] & $70.5 \pm 11.6$ & $66.0 \pm 9.5$ & 0.120 & -6.4 \\
\hline $\begin{array}{l}\text { Urine } 8 \text {-epi PGF2 } \alpha \\
\text { [ng/mmol creatinine] }\end{array}$ & $41.5(23.6-117.4)$ & $30.0(22.0-41.5)$ & 0.063 & -27.7 \\
\hline
\end{tabular}

$B M I$ - body mass index, WC - waist circumference, SBP - systolic blood pressure, DBP - diastolic blood pressure, TCHOL - total cholesterol, $H D L-C$ - high-density lipoprotein cholesterol, LDL-C - low-density lipoprotein cholesterol, TGs - triglycerides, HOMA homeostasis model assessment, $H b A_{1 c}$ - glycated haemoglobin, 25(OH)Vit D - 25-hydroxy vitamin D, iPTH - intact parathyroid hormone, ox-LDL - oxidized LDL, Urine 8-epi PGF2 $\alpha$ - urine 8-isoprostane, NS - nonsignificant. To convert values to mmol/l for triglycerides multiply by 0.01129 , for cholesterol by 0.02586 , for glucose by 0.05551 , and for $25(\mathrm{OH})$ Vit $D$ by $2.5 .{ }^{*} P$ significant at $\leq 0.03$.

of adolescents with obesity with VitD plus dietary intervention was not associated with any changes in ox-LDL, paraoxonase and arylesterase activities (i.e. PON-1 activity was more closely related to PON-1 mass), and urinary isoprostanes.

Recent research has indicated that $25(\mathrm{OH}) \mathrm{VitD}$ may interfere in the regulation of the adipoinsular axis. Some studies in children/adolescents with obesity have found a positive correlation between $25(\mathrm{OH})$ VitD levels and adiponectin compared with controls [39, 40], but this was not confirmed in the present study. Others showed an inverse correlation of $25(\mathrm{OH})$ VitD levels with the leptin/adiponectin ratio [41], and an RCT concluded that serum leptin/adiponectin ratio was significantly lower in the VitD supplemented group compared with the placebo [13]. However, there are no reports to our knowledge of an association between $25(\mathrm{OH})$ VitD and leptin levels alone in children and adolescents. Interestingly, our results showed that $25(\mathrm{OH})$ VitD levels were inversely related to leptin levels (but not to leptin/adiponectin ratio) in adolescents with obesity and that correction of hypovitaminosis D led to a significant $23.3 \%$ reduction of leptin levels after intervention. On the other hand, no differences were seen in the visfatin levels between obese and normal-weight adolescents in the present study and no relationship 
with $25(\mathrm{OH})$ VitD, while we found no relevant data in the literature.

It should be noted that caloric restriction per se might have played a role in the slight decreases in $\mathrm{HbA}_{1} \mathrm{c}$ and leptin levels, although only a non-significant $1.3 \%$ weight reduction was observed.

This study has certain limitations. Firstly, a causal relationship between 25(OH)VitD and CVD risk factors could not be assessed because of the cross-sectional design of the study. Secondly, the number of participants in the prospective study was small, with just over half having VitD deficiency (the rest had insufficiency), while a placebo arm was not included. Thirdly, the supplementation dose (2000 IU/day) and duration (3 months) may have been inadequate to show a significant change in various metabolic markers. Moreover, the actual energy and nutrient intake as well as sunlight exposure of each participant were not precisely calculated.

However, this was a clinically relevant study because it highlights the high incidence of hypovitaminosis $D$ in adolescents with obesity in our country. Moreover, we evaluated the relationship of $25(\mathrm{OH})$ VitD with novel parameters (such as oxLDL, paraoxonase, arylesterase, urine isoprostanes and leptin, adiponectin, visfatin), which have been rarely, if at all, explored in the literature, especially in the adolescent population.

In conclusion, VitD insufficiency/deficiency is very common among Greek adolescents with obesity compared with normal-weight controls. In participants with obesity, 25(OH)VitD was not associated with most of the CVD risk factors, but it was inversely related to leptin. After VitD supplementation along with dietary intervention, we found marginally significant reductions in $\mathrm{HbA}_{1} \mathrm{C}$ and leptin levels but also a significant increase in LDL-C levels.

\section{Acknowledgments}

The authors would like to thank the Atherothrombosis Research Centre of the University of loannina for providing access to the laboratory equipment and facilities.

\section{Conflict of interest}

The authors declare no conflict of interest.

\section{References}

1. Ross AC, Taylor CL, Yaktine AL, et al. Dietary reference intakes for calcium and vitamin D. Institute of Medicine of the National Academies. Washington, DC: The National Academies Press, 2011

2. Sempos CT, Heijboer AC, Bikle DD, et al. Vitamin D assays and the definition of hypovitaminosis $\mathrm{D}$ : results from the First International Conference on Controversies in Vitamin D. Br J Clin Pharmacol 2018; 84: 2194 207.

3. Kumar J, Muntner P, Kaskel FJ, et al. Prevalence and associations of 25-hydroxyvitamin D deficiency in US children: NHANES 2001-2004. Pediatrics 2009; 124 e362-70.

4. Gonzalez-Gross M, Valtuena J, Breidenassel C, et al. Vitamin D status among adolescents in Europe: the Healthy Lifestyle in Europe by Nutrition in Adolescence study. Br J Nutr 2012; 107: 755-64.

5. Manios Y, Moschonis G, Hulshof T, et al. Prevalence of vitamin D deficiency and insufficiency among schoolchildren in Greece: the role of sex, degree of urbanisation and seasonality. Br J Nutr 2017; 118: 550-8.

6. Ng M, Fleming T, Robinson M, et al. Global, regional, and national prevalence of overweight and obesity in children and adults during 1980-2013: a systematic analysis for the Global Burden of disease Study 2013. Lancet 2014; 384: 766-81.

7. Saggese G, Vierucci F, Boot AM, et al. Vitamin D in childhood and adolescence: an expert position statement. Eur J Pediatr 2015; 174: 565-76.

8. Ozcan OU, Gurlek A, Gursoy E, et al. Relation of vitamin D deficiency and new-onset atrial fibrillation among hypertensive patients. J Am Soc Hypertens 2015; 9: 307-12.

9. Kelly AS, Barlow SE, Rao G, et al. Severe obesity in children and adolescents: identification, associated health risks, and treatment approaches: a scientific statement from the American Heart Association. Circulation 2013; 128: 1689-712.

10. Barnard K, Colon-Emeric C. Extraskeletal effects of vitamin $D$ in older adults: cardiovascular disease, mortality, mood, and cognition. Am J Geriatr Pharmacother 2010; 8: 4-33.

11. Cook S, Auinger P, Li C, et al. Metabolic syndrome rates in United States adolescents, from the National Health and Nutrition Examination Survey, 1999-2002. J Pediatr 2008; 152: 165-70.

12. Holick MF, Binkley NC, Bischoff-Ferrari HA, et al. Evaluation, treatment, and prevention of vitamin D deficiency: an Endocrine Society clinical practice guideline. J Clin Endocrinol Metab 2011; 96: 1911-30.

13. Belenchia AM, Tosh AK, Hillman LS, et al. Correcting vitamin D insufficiency improves insulin sensitivity in obese adolescents: a randomized controlled trial. Am J Clin Nutr 2013; 97: 774-81.

14. Garnett SP, Baur LA, Noakes M, et al. Researching Effective Strategies to Improve Insulin Sensitivity in Children and Teenagers - RESIST. A randomised control trial investigating the effects of two different diets on insulin sensitivity in young people with insulin resistance and/ or pre-diabetes. BMC Public Health 2010; 10: 575.

15. Iqbal AM, Dahl AR, Lteif A, et al. Vitamin D deficiency: a potential modifiable risk factor for cardiovascular disease in children with severe obesity. Children 2017; 4: pii: E80.

16. Wortsman J, Matsuoka LY, Chen TC, et al. Decreased bioavailability of vitamin D in obesity. Am J Clin Nutr 2000; 72: 690-3.

17. Kunutsor SK, Apekey TA, Steur M. Vitamin D and risk of future hypertension: meta-analysis of 283,537 participants. Eur J Epidemiol 2013; 28: 205-21.

18. Kao KT, Abidi N, Ranasinha S, et al. Low vitamin D is associated with hypertension in paediatric obesity. J Paediatr Child Health 2015; 51: 1207-13. 
19. Gul A, Ozer S, Yilmaz R, et al. Association between vitamin $D$ levels and cardiovascular risk factors in obese children and adolescents. Nutr Hosp 2017; 34: 323-9.

20. Moore CE, Liu Y. Elevated systolic blood pressure of children in the United States is associated with low serum 25-hydroxyvitamin D concentrations related to body mass index: National Health and Examination Survey 2007-2010. Nutr Res 2017; 38: 64-70.

21. Smith TJ, Tripkovic L, Hauger H, et al. Winter cholecalciferol supplementation at 51 degrees $\mathrm{N}$ has no effect on markers of cardiometabolic risk in healthy adolescents aged 14-18 years. J Nutr 2018; 148: 1269-75.

22. Dolinsky DH, Armstrong S, Mangarelli C, et al. The association between vitamin $\mathrm{D}$ and cardiometabolic risk factors in children: a systematic review. Clin Pediatr 2013; 52: 210-23

23. Sacheck J, Goodman E, Chui K, et al. Vitamin D deficiency, adiposity, and cardiometabolic risk in urban schoolchildren. J Pediatr 2011; 159: 945-50.

24. Oliveira RM, Novaes JF, Azeredo LM, et al. Association of vitamin D insufficiency with adiposity and metabolic disorders in Brazilian adolescents. Public Health Nutr 2013; 17: 787-94.

25. Guasch A, Bullo M, Rabassa A, et al. Plasma vitamin D and parathormone are associated with obesity and atherogenic dyslipidemia: a cross-sectional study. Cardiovasc Diabetol 2012; 11: 149.

26. Ashraf AP, Alvarez JA, Gower BA, et al. Associations of serum 25-hydroxyvitamin $D$ and components of the metabolic syndrome in obese adolescent females. Obesity 2011; 19: 2214-21

27. Kelishadi R, Farajzadegan Z, Bahreynian M. Association between vitamin $\mathrm{D}$ status and lipid profile in children and adolescents: a systematic review and meta-analysis. Int J Food Sci Nutr 2014; 65: 404-10.

28. Nader NS, Aguirre-Castaneda R, Wallace J, et al. Effect of vitamin D3 supplementation on serum 25(OH)D, lipids and markers of insulin resistance in obese adolescents: a prospective, randomized, placebo-controlled pilot trial. Horm Res Paediatr 2014; 82: 107-12.

29. Wang H, Xia N, Yang Y, et al. Influence of vitamin D supplementation on plasma lipid profiles: a meta-analysis of randomized controlled trials. Lipids Health Dis 2012; 11: 42.

30. Pacifico L, Anania C, Osborn JF, et al. Low 25(OH)D3 levels are associated with total adiposity, metabolic syndrome, and hypertension in Caucasian children and adolescents. Eur J Endocrinol 2011; 165: 603-11.

31. Reis JP, von Muhlen D, Miller ER, et al. Vitamin D status and cardiometabolic risk factors in the United States adolescent population. Pediatrics 2009; 124: e371-9.

32. Ferira AJ, Laing EM, Hausman DB, et al. Vitamin D supplementation does not impact insulin resistance in black and white children. J Clin Endocrinol Metab 2016; 101: 1710-8.

33. Sethuraman U, Zidan MA, Hanks L, et al. Impact of vitamin D treatment on 25 hydroxy vitamin D levels and insulin homeostasis in obese African American ado lescents in a randomized trial. J Clin Transl Endocrinol 2018; 12: 13-9.

34. MacDonald K, Godziuk K, Yap J, et al. Vitamin D status, cardiometabolic, liver, and mental health status in obese youth attending a pediatric weight management center. J Pediatr Gastroenterol Nutr 2017; 65: 462-6.

35. Javed A, Vella A, Balagopal PB, et al. Cholecalciferol supplementation does not influence beta-cell function and insulin action in obese adolescents: a prospective double-blind randomized trial. J Nutr 2015; 145: 284-90.
36. Erdonmez D, Hatun S, Cizmecioglu FM, et al. No relationship between vitamin $D$ status and insulin resistance in a group of high school students. J Clin Res Pediatr Endocrinol 2011; 3: 198-201.

37. Brar PC, Contreras M, Fan X, et al. Effect of one time high dose "stoss therapy" of vitamin D on glucose homeostasis in high risk obese adolescents. Arch Endocrinol Metab 2018; 62: 193-200.

38. Grunwald T, Fadia S, Bernstein B, et al. Vitamin D supplementation, the metabolic syndrome and oxidative stress in obese children. J Pediatr Endocrinol Metab 2017; 30: 383-8.

39. Kardas F, Kendirci M, Kurtoglu S. Cardiometabolic risk factors related to vitamin $\mathrm{D}$ and adiponectin in obese children and adolescents. Int J Endocrinol 2013; 2013: 503270.

40. Giudici KVP, Fisberg RM, Marchioni DML, et al. Crosstalk between bone and fat tissue: associations between vitamin D, osteocalcin, adipokines, and markers of glucose metabolism among adolescents. J Am Coll Nutr 2017; 36: 273-80.

41. Rambhojan C, Larifla L, Clepier J, et al. Vitamin D status, insulin resistance, leptin-to-adiponectin ratio in adolescents: results of a 1-year lifestyle intervention. Open Access Maced J Med Sci 2016; 4: 596-602. 